\title{
Pengaruh inovasi produk terhadap minat beli pada usaha tekat tiga dara di Kota Pekanbaru
}

\author{
Siti Viona ${ }^{1^{*}}$, Rosmayani $^{2}$ \\ ${ }^{1,2}$ Fakultas Ekonomi dan Bisnis Universitas Islam Riau \\ *Correspondent email: sitiviona@gmail.com
}

\begin{abstract}
The research conducted by the author aims to determine the effect of the Product Innovation variable on the Buying Interest variable in the Tekat Tiga Dara business in Pekanbaru City, the phenomena raised include making new innovations to improve product quality, product innovation both in terms of increasing prices and values. use the product in order to create the features of the products sold, prioritizing Malay characteristics, The level of consumer buying interest in Tekat Tiga Dara products occurs because of the attractiveness of each unique product, and consumers tend to buy Tekat Tiga Dara products because of the desire for new product innovations. resulting from. This type of research is descriptive with quantitative methods. The sampling technique used incidental sampling technique with a total sample of 50 respondents, the data used in the study were obtained through observation, interviews, questionnaires and literature studies, the types of data sources used in this study were primary data and secondary data then data analysis techniques used in this study This research includes Validity Test, Reliability Test, T Test, Simple Coefficient of Determination, Statistical Hypothesis, and Simple Linear Regression using SPSS v.22. For the results of the tests carried out, the results showed that the product innovation variable affected buying interest in the business of three virgins in the city of Pekanbaru.
\end{abstract}

Keywords: Buying Interest Product Innovation, Tekat Tiga Dara Products in Pekanbaru City

\section{PENDAHULUAN}

Semakin majunya perkembangan ilmu pengetahuan dan teknologi sangat berpengaruh dalam bidang usaha. Hal ini mendorong para pengusaha untuk menghasilkan produk dalam jumlah besar dan jenis yang lebih bervariasi serta kualitas yang memadai. Inovasi produk menurut Bussines Dictionary (dalam Dewanto, 2015;105) Inovasi produk bukan hanya merupakan sebuah pengembangan produk, namun inovasi produk juga dapat berupa pengenalan produk baru, mengonsep ulang dalm rangka meningkatkan barang atau jasa yang dihasilkan oleh sebuah perusahaan. Berkembangnya industri dewasa ini menyebabkan makin kompetitifnya persaingan dalam dunia industri di mana perusahaan berlombalomba untuk menarik konsumen sebanyak mungkin. Para pelaku bisnis di industri terus berupaya agar apa yang mereka hasilkan dan mereka tawarkan, diinginkan dan diterima oleh konsumen, yang kemudian akan dibeli dalam tingkat pembelian yang maksimum dengan frekuensi pembelian yang tinggi.

Peran UKM dalam perekonomian suatu negara sangatlah penting UKM melambangkan kekuatan pembangunan ekonomi sebuah negara, Pentingnya UKM sebagian besar berkaitan dengan sebutan mereka sebagai tulang punggung ekonomi pembangunan. Kehadiran UKM dapat merangsang inisiatif, inovasi dan semangat kewirausahaan secara keseluruhan. Untuk itu dengan adanya inovasi produk yang merupakan hasil dari pengembangan produk baru oleh suatu perusahaan atau industri, baik yang sudah ada maupun belum.

Inovasi harus dilakukan secara berkelanjutan oleh perusahaan atau industri karena sudah merupakan kebutuhan mendasar agar mampu menciptakan pembaharuan produk baru dalam bersaing serta untuk mengganti produk lama menjadi produk yang lebih baru, penggantian ini dapat terus meningkatkan keinginan konsumen untuk membeli produk tersebut.

Minat merupakan salah satu aspek psikologis yang mempunyai pengaruh cukup besar terhadap perilaku, dan minat juga merupakan sumber motivasi yang akan mengarahkan seseorang dalam melakukan apa yang mereka lakukan. Minat beli juga dapat timbul apabila seorang konsumen merasa sangat tertarik terhadap berbagai informasi seputar produk yang diperoleh melalui iklan, pengalaman orang yang telah menggunakannya, dan kebutuhan yang mendesak terhadap suatu produk. Minat beli menurut Kinnear dan Taylor, 2003 dalam Sukmawati, 1994, yaitu merupakan bagian dari komponen 


\section{SYNERGY}

Vol 1, No 2, Oktober 2021, p. 62-69

Jurnal Bisnis dan Manajemen

perilaku konsumen dalam sikap mengkonsumsi, kecenderungan responden untuk bertindak sebelum keputusan membeli benar-benar dilaksanakan.

Tekat Tiga Dara adalah salah satu UKM yang bergerak di bidang kerajinan tangan khas Riau beralamat di Jalan Dahlia Gang Jati Nomor 5, Komplek Kejaksaan, Kelurahan Rejosari, Kecamatan Sukajadi, Pekanbaru berdiri sejak tahun 2009. Pemilik Tekat Tiga Dara yaitu Ibu Tengku Syarifah Nurila Zaharazad, hasil karyanya ini telah mulai dikenal di berbagai pelosok daerah di tanah air dan beberapa pemesan dari negara luar.

\section{METODE PENELITIAN}

\section{Tipe Penelitian}

Metode yang digunakan oleh peneliti menggunakan metode kuantitatif digunakan untuk meneliti pada populasi atau sampel tertentu, pengumpulan data menggunakan instrumen penelitian, analisis data bersifat kuantitatif/statistik, dengan tujuan untuk menggambarkan dan menguji hipotesis yang telah ditetapkan (Sugiyono, 2017).

\section{Lokasi Penelitian}

Lokasi usaha Tekat Tiga Dara beralamat di jalan Dahlia No. 5 Gg.jati Komplek Kejaksaan Kecamatan Sukajadi Kota Pekanbaru. Alasan penulis mengambil lokasi penelitian di UKM Tekat Tiga Dara karena UKM Tekat Tiga Dara merupakan salah satu pengrajin sulam tekat mancanegara yang masih selalu mengutamakan sentuhan seni tradisional yang kental serta mengutamakan keunikan bentuk yang dimilki produk tersebut untuk itu kekhasan melayu tetap menjadi proiritas bagi produknya agar tidak hilang di bumi melayu.

\section{Populasi dan Sampel}

Populasi dari penelitian ini adalah semua konsumen yang pernah membeli produk Tekat Tiga Dara yang semua konsumennya berjumlah tak terhingga. Adapun yang menjadi sampel dalam penelitian ini yang bersifat mewakili ditetapkan 50 orang konsumen pada UKM Tekat Tiga Dara dengan ketentuan sudah pernah melakukan pembelian minimal 2 kali. Diperoleh sampel sebanyak 50 orang tersebut sudah cukup repsentatif atau mewakili untuk dapat menjawab permasalahan dalam penelitian ini.

\section{Teknik Penarikan Sampel}

Dalam penelitian ini penulis menggunakan teknik penarikan sampel sampling insidental. Sampling Insidental adalah teknik penentuan sampel berdasarkan kebetulan, yaitu siapa saja yang secara kebetulan/ insidental bertemu dengan peneliti dapat digunakan sebagai sampel, apabila dipandang orang yang kebetulan ditemui tersebut dapat dijadikan sebagai sumber data. (Sugiyono,2012).

\section{HASIL DAN PEMBAHASAN}

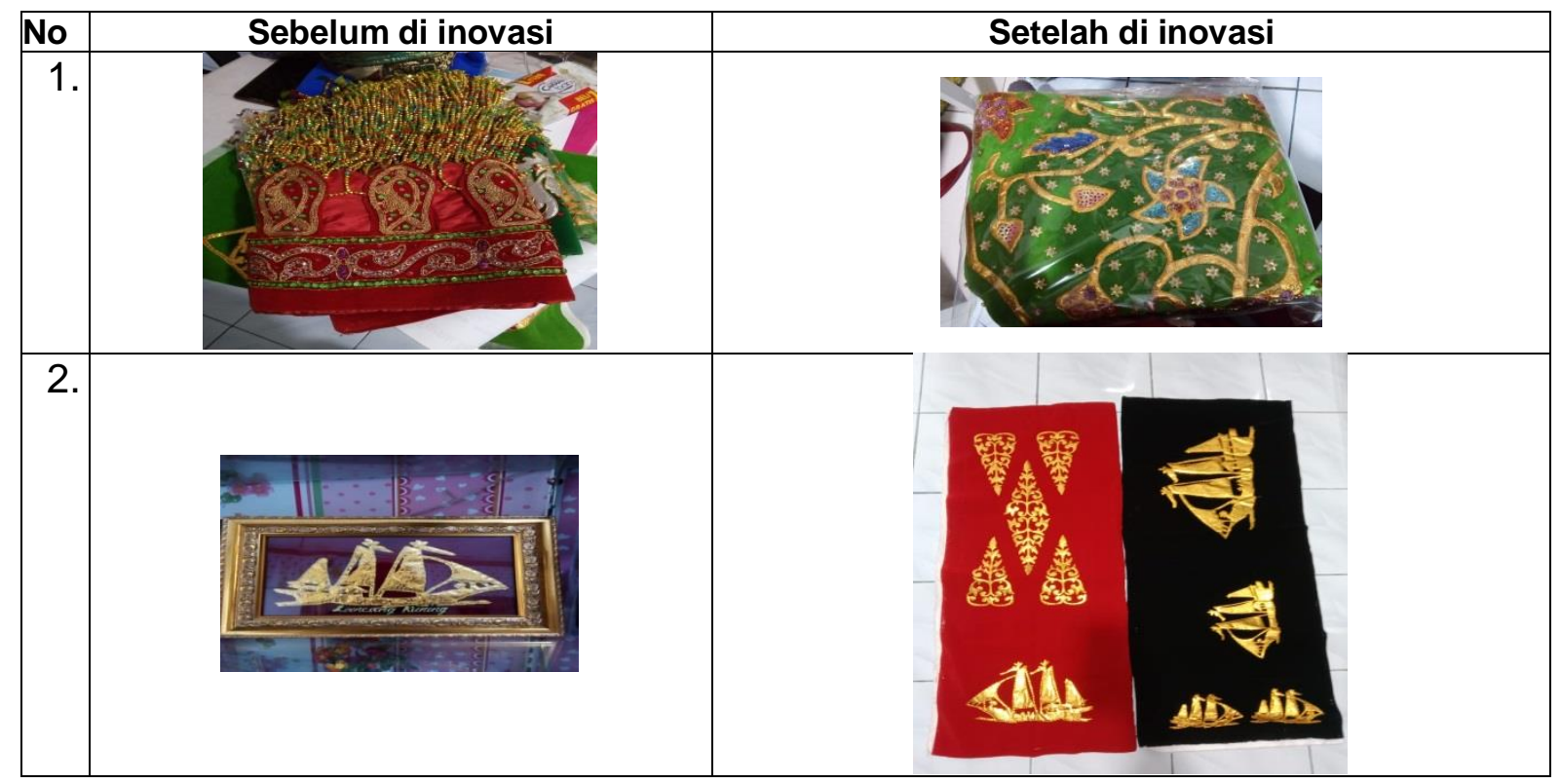




\section{SYNERGY}

Vol 1, No 2, Oktober 2021, p. $62-69$

Jurnal Bisnis dan Manajemen

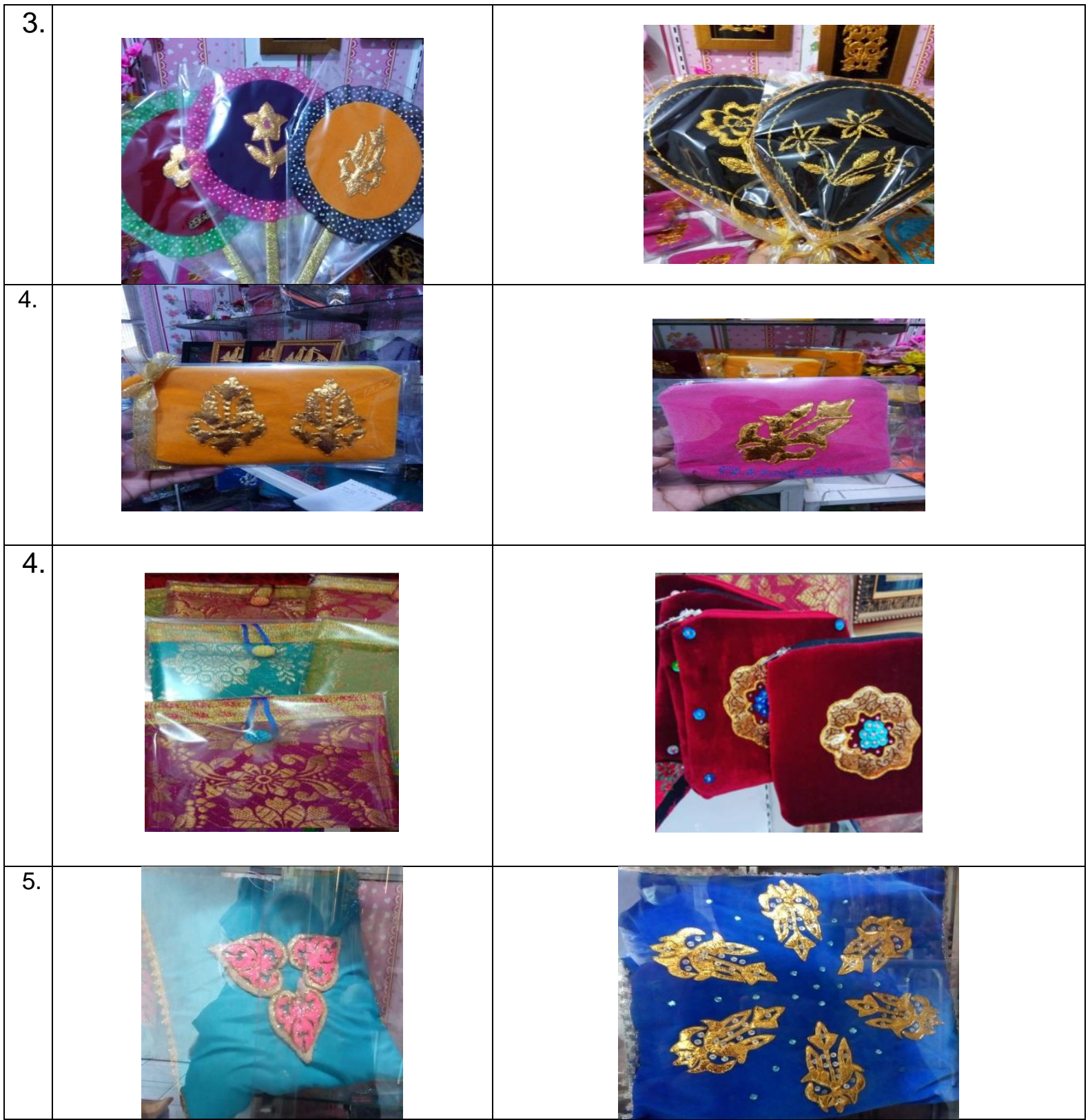

Gambar 1. Daftar Produk Sulam Tekat Tiga Dara Kota Pekanbaru Sumber: Observasi Tekat Tiga Dara, 2020

Dari tabel diatas dapat kita lihat bahwa Tekat Tiga Dara membuat inovasi olahan kerajinan tangan yang menggunakan benang prada emas menjadi berbagai macam produk kerajinan tangan dan souvenir yang bernilai tinggi. Inovasi-inovasi yang dilakukan oleh Tekat Tiga Dara ini sejalan dengan pendapat suryani, yang menyatakan bahwa" salah satu cara yang harus dilakukan oleh pelaku usaha yaitu dengan melakukan inovasi pada produknya"(Suryani,2008:5), agar produk yang dihasilkan oleh Tekat Tiga Dara ini terkenal hingga keluar daerah Riau. Selama menjalankan usahanya UKM Tekat Tiga Dara memiliki 10 anggota tetap.

\section{Identitas Responden Jenis Kelamin}

Tabel 1. Karakteristik Responden Berdasarkan Jenis Kelamin pada Tekat Tiga Dara di Kota Pekanbaru

\begin{tabular}{|c|c|c|c|}
\hline No & Jenis Kelamin & Jumlah & Persentase $\%$ \\
\hline 1 & Laki-Laki & 10 & $20 \%$ \\
\hline 2 & Perempuan & 40 & $80 \%$ \\
\hline \multicolumn{2}{|c|}{ Jumlah } & 50 & $100 \%$ \\
\hline
\end{tabular}

Sumber : Data Olahan Penulis, 2021 
Berdasarkan Tabel 1 diatas maka dapat disimpulkan bahwa responden perempuan lebih dominan sebanyak 40 orang dengan persensate dan dibandingkan jumlah responden laki - laki sebanyak 10 orang dengan persentase dari keseluruhan responden konsumen pada usaha Tekat Tiga Dara di Kota Pekanbaru.

\section{Tingkat Pendidikan}

Tabel 2. Klasifikasi Jumlah Responden Berdasarkan Tingkat Pendidikan Pada Usaha Tekat Tiga Dara di Kota Pekanbaru

\begin{tabular}{|c|l|c|c|}
\hline No & Tingkat Pendidikan & Jumlah & Persentase (\%) \\
\hline 1 & SMA & - & - \\
2 & Diploma (D3) & 5 & $10 \%$ \\
\hline 3 & Sarjana (S1) & 25 & $50 \%$ \\
\hline 4 & Magister (S2) & 20 & $40 \%$ \\
\hline \multicolumn{2}{|c|}{ Total } & 50 & $100 \%$ \\
\hline
\end{tabular}

Sumber: Data Olahan Penulis, 2021

Pada tabel diatas, dapat dilihat bahwa tingkat pendidikan responden bervariasi yakni, responden tingkat pendidikan terakhir SMA tidak ada orang dengan persentase kemudian responden tingkat pendidikan terakhir Diploma (D3) berjumlah 5 orang dengan persentase $10 \%$, selanjutnya responden tingkat pendidikan terakhir Sarjana (S1) berjumlah 25 orang dengan persentase $50 \%$, serta responden tingkat pendidikan terakhir Magister berjumlah 20 orang dengan persentase $40 \%$. Sehingga responden berdasarkan tingkat pendidikan terakhir yang terbanyak melakukan pembelian pada usaha Tekat Tiga Dara di Kota Pekanbaru yaitu responden dengan tingkat pendidikan terakhir Sarjana (S1) sebanyak 25 orang.

\section{Pekerjaan}

Tabe1 3. Klasifikasi Jumlah Responden berdasarkan Pekerjaan Pada Usaha Tekat Tiga Dara Di Kota Pekanbaru

\begin{tabular}{|c|l|c|c|}
\hline No & \multicolumn{1}{|c|}{ Pekerjaan } & Jumlah & Persentase (\%) \\
\hline 1 & Pelajar/Mahasiswa & 2 & $4 \%$ \\
\hline 2 & Pegawai Negeri & 25 & $50 \%$ \\
\hline 3 & $\begin{array}{l}\text { Pegawai Terlatih } \\
\text { (Dokter,Perawat,Bidan,dll) }\end{array}$ & 10 & $20 \%$ \\
\hline 4 & Pegawai Swasta & 10 & $20 \%$ \\
\hline 5 & IRT (Ibu Rumah Tangga) & 3 & $6 \%$ \\
\hline \multicolumn{2}{|c|}{ Total } & 50 & $100 \%$ \\
\hline
\end{tabular}

Sumber: Data Olahan Penulis,2021

Berdasarkan tabel 3 diatas, dapat diketahui jumlah responden berdasarkan pekerjaan terdiri dari 2 orang pelajar/mahasiswa dengan persentase $4 \%$, kemudian responden berdasarkan pekerjaan pegawai negeri sejumlah 25 orang dengan persentase $50 \%$, responden berdasarkan pekerjaan pegawai terlatih sejumlah 10 orang dengan persentase $20 \%$, responden berdasarkan pekerjaan pegawai swasta sejumlah 8 orang dengan persentase $20 \%$, serta responden berdasarkan IRT sejumlah 3 orang dengan persentase $6 \%$.

\section{Kunjungan}

Tabel 4. Karakteristik Responden Berdasarkan Kunjungan

\begin{tabular}{|c|c|c|c|}
\hline No. & Kunjungan Pembelian & Jumlah & Persentase (\%) \\
\hline 1 & 2 kali & 6 & $12 \%$ \\
\hline 2 & 3 kali & 5 & $10 \%$ \\
\hline 3 & Sering & 21 & $42 \%$ \\
\hline 4 & Berulang Kali & 18 & $36 \%$ \\
\hline
\end{tabular}

Sumber: Data Olahan Penulis, 2021 


\section{SYNERGY}

Vol 1, No 2, Oktober 2021, p. $62-69$

Jurnal Bisnis dan Manajemen

e-ISSN : 2777-0346 | p-ISSN : 2777-0354

Dari tabel diatas Jumlah kunjungan per 3 bulan terakhir tahun 2021, bahwa responden Tekat Tiga Dara di Pekanbaru dengan tingkat kunjungan pembelian yaitu: 2 kali sebanyak 6 orang ,kunjungan 3 kali sebanyak 5 orang, kunjungan sering sebanyak 21 orang dan kunjungan berulang kali sebanayak 18 orang . maka dapat disimpulkan, responden yang menjadi 21 orang yang paling banyak melakukan pembelian sering di Tekat Tiga Dara di Pekanbaru.

\section{Omset Penjualan}

Tabel 5. Omset Penjualan Usaha Tekat Tiga Dara di Kota Pekanbaru

\begin{tabular}{|c|c|c|}
\hline No. & Tahun & Jumlah \\
\hline 1 & 2017 & Rp 49.200.000 \\
\hline 2 & 2018 & Rp 57.410.000 \\
\hline 3 & 2019 & Rp 68.256.000 \\
\hline
\end{tabular}

Sumber : Data Olahan Penulis, 2021

Berdasarkan tabel 5 dapat diketahui bahwa jumlah pendapatan pada UKM Tekat Tiga Dara mengalami kenaikan setiap tahunnya dapat dilihat pada tahun 2017 mendapatkan omset Rp 49.200.000 merupakan pendapatan yang diperoleh dengan penjualan sistem online, dimana pada tahun 2017 penjualan produk tidak sebanyak penjualan produk pada tahun 2018 yang berjumlah Rp 57.410.000, dan pada penjualan tahun 2019 tekat tiga dara mulai mengikuti bazar dimana adanya suatu event yang berkaitan dengan keragam melayu serta dari situ banyak orang yang tertarik lalu memesan sebagai cendramata maka penjualan produk meningkat sebanyak Rp 68.256.000.

\section{Variabel dan Indikator Variabel}

Tabel 6. Rekapitulasi Tanggapan Responden Mengenai Variabel Inovasi Produk Pada Usaha Tekat Tiga Dara Di Kota Pekanbaru

\begin{tabular}{|c|l|c|c|c|c|c|c|c|l|}
\hline \multirow{2}{*}{ No } & \multirow{2}{*}{ Keterangan } & \multicolumn{5}{|c|}{ Tanggapan Reponden } & \multirow{2}{*}{ Jumlah } & \multirow{2}{*}{ Bobot } & \multirow{2}{*}{ Kategori } \\
\cline { 3 - 9 } & & SS & S & KS & TS & STS & & & \\
\hline 1 & Fitur & 55 & 54 & 7 & 3 & 1 & 150 & 669 & $\begin{array}{l}\text { Sangat } \\
\text { setuju }\end{array}$ \\
\hline 2 & Desain Produk & 129 & 55 & 9 & 5 & 2 & 200 & 904 & $\begin{array}{l}\text { Sangat } \\
\text { setuju }\end{array}$ \\
\hline 3 & Kualitas Produk & 85 & 54 & 7 & 3 & 1 & 150 & 669 & $\begin{array}{l}\text { Sangat } \\
\text { setuju }\end{array}$ \\
\hline \multicolumn{2}{|c|}{ Jumlah } & 269 & 163 & 23 & 11 & 4 & 500 & 2.242 & $\begin{array}{l}\text { Sangat } \\
\text { setuju }\end{array}$ \\
\hline
\end{tabular}

Sumber :Data Olahan Penulis 2021

Berdasarkan Tabel 6 rekapitulasi tanggapan responden variabel inovasi bahwa indikator Fitur memiliki bobot 669, indikator Desain Produk memiliki bobot 904, dan indikator Kualitas Produk memiliki bobot 669. Total bobot yang diperoleh dari variabel Inovasi Produk sejumlah 2.242, berdasarkan tabel interval variabel Inovasi Produk 2100 - 2500 termasuk ke dalam kategori sangat setuju.

Berdasarkan hasil rekapitulasi tersebut, penilaian tertinggi oleh responden adalah indikator Desain Produk. Item yang mendukung penampilan serta memiliki kualitas yang baik untuk digunakan oleh konsumen, dan desain produk juga mempengaruhi minat konsumen terhadap suatu barang yang akan dipilihnya.

Tabel 7. Rekapitulasi Tanggapan Responden Mengenai Variabel Minat Beli Pada Usaha Tekat Tiga Dara Di Kota Pekanbaru

\begin{tabular}{|c|c|c|c|c|c|c|c|c|c|}
\hline \multirow[b]{2}{*}{ No } & \multirow[b]{2}{*}{ Keterangan } & \multicolumn{5}{|c|}{ Tanggapan Reponden } & \multirow{2}{*}{$\begin{array}{c}\text { Jumla } \\
h\end{array}$} & \multirow[b]{2}{*}{ Bobot } & \multirow{2}{*}{ Kategori } \\
\hline & & SS & $\mathrm{S}$ & KS & TS & STS & & & \\
\hline 1 & Ketertarikan & 74 & 66 & 6 & 3 & 1 & 150 & 659 & Sangat setuju \\
\hline 2 & Keinginan & 102 & 90 & 6 & 2 & 0 & 200 & 889 & Sangat setuju \\
\hline 3 & Keyakinan & 70 & 69 & 8 & 2 & 1 & 150 & 665 & Sangat setuju \\
\hline & Jumlah & 246 & 225 & 20 & 7 & 2 & 500 & 2213 & Sangat Setuju \\
\hline
\end{tabular}

Sumber :Data Olahan Penulis 2021 
Berdasarkan tabel Rekapitulasi tanggapan responden variabel Minat Beli indikator Ketertariakn memiliki bobot 659 , indikator Keinginan memiliki bobot 889 , dan indikator Keyakinan memiliki bobot 665. Total bobot yang diperoleh variabel Minat Beli sejumlah 2213, bedasarkan tabel interval variabel Minat Beli pada 2100 - 2500 dan termasuk ke dalam kategori sangat setuju. Berdasarkan hasil rekapitulasi tersebut, penilaian tertinggi oleh responden adalah untuk indikator Keinginan.

\section{Hasil Teknik Analisis Data Uji Validitas}

Tabel 8. Hasil Analisis Validitas Variabel Inovasi Produk (X) dan Variabel Minat Beli (Y)

\begin{tabular}{|c|c|c|c|c|}
\hline Variabel & Pernyataan & $\mathrm{r}_{\text {hitung }}$ & $\mathrm{r}_{\text {tabel }}$ & Keputusan \\
\hline \multirow{4}{*}{ Inovasi Produk (X) } & $\mathrm{X} 1$ & 0,611 & 0,279 & Valid \\
\cline { 2 - 5 } & $\mathrm{X} 2$ & 0,713 & 0,279 & Valid \\
\cline { 2 - 5 } & $\mathrm{X} 3$ & 0,582 & 0,279 & Valid \\
\cline { 2 - 5 } & $\mathrm{X} 4$ & 0,442 & 0,279 & Valid \\
\cline { 2 - 5 } & $\mathrm{X} 5$ & 0,481 & 0,279 & Valid \\
\cline { 2 - 5 } & $\mathrm{X} 6$ & 0,300 & 0,279 & Valid \\
\cline { 2 - 5 } & $\mathrm{X} 7$ & 0,423 & 0,279 & Valid \\
\cline { 2 - 5 } & $\mathrm{X} 8$ & 0,611 & 0,279 & Valid \\
\cline { 2 - 5 } & $\mathrm{X} 9$ & 0,713 & 0,279 & Valid \\
\hline \multirow{5}{*}{ MinatBeli (Y) } & $\mathrm{Y} 1$ & 0,582 & 0,279 & Valid \\
\cline { 2 - 5 } & $\mathrm{Y} 2$ & 0,441 & 0,279 & Valid \\
\cline { 2 - 5 } & $\mathrm{Y} 3$ & 0,592 & 0,279 & Valid \\
\cline { 2 - 5 } & $\mathrm{Y} 4$ & 0,353 & 0,279 & Valid \\
\cline { 2 - 5 } & $\mathrm{Y} 5$ & 0,389 & 0,279 & Valid \\
\cline { 2 - 5 } & $\mathrm{Y} 6$ & 0,520 & 0,279 & Valid \\
\cline { 2 - 5 } & $\mathrm{Y} 7$ & 0,543 & 0,279 & Valid \\
\cline { 2 - 5 } & $\mathrm{Y} 8$ & 0,465 & 0,279 & Valid \\
\cline { 2 - 5 } & $\mathrm{Y} 9$ & 0,665 & 0,279 & Valid \\
\hline
\end{tabular}

Sumber: Data Olahan Penulis, 2021 Berdasarkan tabel diatas variabel Inovasi Produk (X) $\mathrm{r}$ hitung $>r$ table didapatkan $n=50$ sebesar 0,279 dengan taraf signifkan 5\%. Merujuk pada hasil dari uji validitas bahwa semua item pada variabel $\mathrm{X}$ yang dimulai dari $\mathrm{X} 1, \mathrm{X} 2, \mathrm{X} 3, \mathrm{X} 4, \mathrm{X} 5, \mathrm{X} 6$ $, \mathrm{X} 7, \mathrm{X} 8, \mathrm{X} 9, \mathrm{X} 10$ dinyatakan valid karena nilai $\mathrm{r}_{\text {hitung }}>\mathrm{r}_{\text {tabel. }}$ Demikian pada variabel $\mathrm{Y}$ yang terdiri atas $\mathrm{Y} 1, \mathrm{Y} 2, \mathrm{Y} 3, \mathrm{Y} 4, \mathrm{Y} 5, \mathrm{Y} 6, \mathrm{Y} 7, \mathrm{Y} 8, \mathrm{Y} 9, \mathrm{Y} 10$ juga menghasilkan nilai $\mathrm{r}$ hitung $>\mathrm{r}$ tabel. maka dari itu dapat disimpulkan bahwa semua instrumen pada penelitian ini dinyatakan valid.

\section{Uji Reabilitas}

Tabel 9. Hasil Uji Reabilitas

\begin{tabular}{|c|c|c|c|}
\hline Variabel & $\begin{array}{c}\text { Cronbach's } \\
\text { Alpha }\end{array}$ & $\begin{array}{c}\text { Ketentuan } \\
\text { Reliabel }\end{array}$ & Keterangan \\
\hline Inovasi Produk & 0,733 & 0,60 & Reliabel \\
\hline Minat Beli & 0,623 & 0,60 & Reliabel \\
\hline
\end{tabular}

Sumber : Data Olahan Penulis 2021

Berdasarkan tabel diatas maka dapat disimpulkan bahwa Inovasi Produk (X) nilai Cronbach`s Alpha sebesar 0,733 > 0,60 maka dapat dikatakan data $\mathrm{X}$ reliabel, dan pada Minat Beli (Y) nilai Cronbach`s Alpha sebesar 0,623>0,60 dapat diartikan pengujian data Y reliabel. 3. Analisis Linier Regres 


\section{Analisis Linier Regresi}

Tabel 10. Analisis Linier Sederhana

\begin{tabular}{|c|c|c|c|c|c|}
\hline \multirow[b]{3}{*}{ Model } & & Coefficients $^{\mathrm{a}}$ & & \multirow[b]{3}{*}{$\mathrm{T}$} & \multirow[b]{3}{*}{ Sig. } \\
\hline & \multicolumn{2}{|c|}{ Unstandardized Coefficients } & $\begin{array}{l}\text { Standardized } \\
\text { Coefficients }\end{array}$ & & \\
\hline & $\mathrm{B}$ & Std. Error & Beta & & \\
\hline 1 (Constant) & 6.712 & 1.673 & & 4.011 & .000 \\
\hline Inovasi Produk & .338 & .037 & .796 & 9.113 & .000 \\
\hline
\end{tabular}

Sumber : Data Olahan Penulis, 2021

Berdasarkan perhitungan SPSS versi 22 tersebut diperoleh persamaan linier sederhana sebagai berikut :

$$
\mathrm{Y}=6.712+0,338 \mathrm{X}
$$

Dari persamaan linier sederhana diatas diperoleh nilai konstanta sebesar 6.712 artinya variabel Minat Beli dipengaruhi oleh variabel bebasnya bernilai 1 maka besarnya rata - rata Minat Beli pelanggan adalah 6.712. setiap kenaikan $1 \%$ pada inovasi produk mempengaruhi kenaikan pada variabel minat beli sebesar 0,338. Untuk mengetahui hasil uji $\mathrm{T}$ pada variabel kualitas produk terhadap minat beli adalah sebagai berikut :

$$
\begin{aligned}
& \mathrm{t} \text { tabel }=(\alpha / 2 ; \mathrm{n}-2) \\
& \mathrm{t} \text { tabel }=(0,1 / 2 ; 50-2) \\
& \mathrm{t} \text { tabel }=0,05 ; 48 \text { maka ditemukan nilai } \mathrm{t} 6.712
\end{aligned}
$$

Berdasarkan hasil analisis regresi diperoleh nilai t hitung sebesar $9.113>6.712$ dan nilai signifikan adalah $0,00<0,1$, maka dapat disimpulkan bahwasannya terdapat hubungan yang signifikan dari variabel independen terhadap variabel dependen.

\section{Uji Determinasi}

Tabel 11. Hasil Uji $\mathrm{R}^{2}$

Model Summary

\begin{tabular}{|l|r|r|r|r|}
\hline Model & $\mathrm{R}$ & R Square & \multicolumn{1}{c|}{$\begin{array}{c}\text { Adjusted R } \\
\text { Square }\end{array}$} & $\begin{array}{c}\text { Std. Error of } \\
\text { the Estimate }\end{array}$ \\
\hline 1 & $.796^{\mathrm{a}}$ & .634 & .626 & 1.05734 \\
\hline
\end{tabular}

Sumber : Data Olahan Penulis, 2021

Berdasarkan tabel 11 diatas diketahui nilai $\mathrm{R}^{2}$ adalah sebesar 0,634 atau $(63,40 \%)$ Hal ini berarti bahwa Inovasi Produk berpengaruh terhadap Minat Beli konsumen pada Usaha Tekat Tiga Dara di Kota Pekanbaru. Sedangkan sisanya sebesar 36,60\% (100\% - 63,40\%) dipengaruhi oleh faktor lain yang tidak diamati dalam penelitian ini seperti: (promosi, daya saing, volume penjualan) dan seterusnya.

\section{KESIMPULAN}

Variabel X (Inovasi Produk) dan variabel Y (Minat Beli) dengan jumlah sampel yang diambil sebanyak 50 responden, maka dapat di disimpulkan sebagai berikut:

1. Pengaruh Inovasi Produk yang dilakukan pada usaha ini berpengaruh positif terhadap Minat Beli di Tekat Tiga Dara di kota pekanbaru adapun inovasi yang dilakukan pada produk : Tirai sulam , Kipas Tekat Galang, Souvenir lancang kuning Tekat, Dompet Tekat, dan sarung bantal prada.

2. Inovasi produk pada usaha Tekat Tiga Dara di Kota Pekanbaru dikategorikan sangat setuju . Data tersebut diperoleh dari hasil kusioner kepada konsumen yang sudah berlanganan, menyatakan bahwa konsumen bisa memesan sesuai desain atau pesanan yang mereka inginkan serta konsumen percaya pesanan akan berkualitas baik.

3. Minat Beli pada Tekat Tiga Dara di Kota Pekanbaru ini dikategorikan Sangat Setuju. Data tersebut diperoleh dari hasil kusioner yang berlangganan. Produk yang dijual kebanyakan yang membeli pegawai dinas di daerah lokasi tempat usaha tersebut serta mereka yakin dengan produk Tekat Tiga Dara ini karena ditempat dinas tersebut sudah pernah melakukan bazar maka dari itu mereka tertarik untuk membeli sebagai cendramata atau bingkisan untuk acara - acara formal atau non formal. 


\section{UCAPAN TERIMAKASIH}

Terimakasih kepada semua pihak yang telah membantu penelitian ini.

\section{DAFTAR PUSTAKA}

Sugiyono. 2012. Metode Penelitian Kuantitatif Kualitatif dan R\&B. Bandung: Alfabeta.

Sugiyono,2017, Metode Penelitian Kuantitatif, Kualitatif, dan R\&D, Bandung : Alfabeta

Sukmawati dan A Suyono, 1994. "Analisis Pengaruh Karakteristik Bintang Idola Iklan (Celebrity Endoser) Terhadap Minat Beli Konsumen Sebuah Merek Multivitamin (Studi Pada Mahasiswa Fakultas Ekonomi Universitas Sebelas Maret)". Jurnal Manajemen dan Kewirausahaan, vol 3 no 1, Maret

Wawan Dewanto dkk, 2013. Manajemen inovasi, Bandung : Penerbit Andi

Wawan Dewanto, 2014. Manajemen Inovasi Untuk Usaha Kecil Dan Mikro,Bandung 